\title{
Early-Stage Breast Cancer - Highlights at ASCO 2006
}

\author{
Sebastian F. Schoppmann Raimund Jakesz \\ Department of Surgery, Medical University of Vienna, Austria
}

\begin{abstract}
Key Words
American Society of Clinical Oncology - Early breast cancer - Excision margins - Vitamin D . Clodronate . HER2/neu · Trastuzumab · Circulating tumor cells
\end{abstract}

\section{Summary}

The goal of the American Society of Clinical Oncology (ASCO) is to advance the education of physicians and other professionals caring for patients with cancer, to provide and support the development of clinical cancer research and to advance the delivery of high-quality health care to patients with cancer. During the ASCO Annual Meeting, data from large international and multicenter studies dealing with concerns of therapeutic proceedings of breast cancer are presented. Moreover, results from basic research and upcoming preclinical therapeutical and diagnostic issues are presented. The aim of this short review is to provide insight into a selected number of presentations from the 42nd ASCO Annual Meeting, June 2-6 2006, in Atlanta, Georgia. Abstracts dealing with the topics of excision margins, interstitial high dose rate brachytherapy, adjuvant HER2/neu-associated therapies and the role of circulating tumor cells in early-stage breast cancer are subsumed, evaluated and discussed. It was intended to mainly integrate abstracts presented at smaller oral or poster sessions into this summary.

\section{Margin Status in Breast-Conserving Surgery of Early-Stage Breast Cancer}

The importance of margin status in breast-conserving treatment of early-stage breast cancer is controversial. Most would agree that negative margins are preferable to close or positive

\author{
Schlüsselwörtel \\ American Society of Clinical Oncology · Brustkrebs-Früh- \\ stadium · Resektionsränder · Vitamin D · Clodronate . \\ HER2/neu - Trastuzumab - Zirkulierende Tumorzellen
}

\section{Zusammenfassung}

Aufgabe der American Society of Clinical Oncology (ASCO) ist es, die Aus- und Weiterbildung von Ärzten und anderen Berufsgruppen, die mit Krebspatienten beschäftigt sind, zu fördern und zu unterstützen. Während des jährlich abgehaltenen ASCO Annual Meeting werden neue große internationale Studien und deren Ergebnisse über Behandlungskonzepte beim Mammakarzinom vorgestellt. Zusätzlich werden grundlagenwissenschaftliche Projekte und vorklinische Studien präsentiert. In dieser kurzen Übersicht soll eine Auswahl an Studien, die auf dem 42. ASCO Annual Meeting (2.-6. Juni 2006, Atlanta, Georgia) präsentiert wurden, zusammengefasst werden. Präsentationen mit den Themen Resektionsränder, interstitielle Hochdosis-Brachytherapy, adjuvante HER2/neuassoziierte Therapien und die Rolle von zirkulierenden Tumorzellen beim frühen Mammakarzinom sollen zusammengefasst, evaluiert und diskutiert werden. Besonderes Augenmerk wurde auf Studien gelegt, die während des Kongresses in kleineren Sitzungen und Posterpräsentationen vorgestellt wurden.

\begin{tabular}{ll}
\hline KARGER & ๑ 2006 S. Karger GmbH, Freiburg \\
Fax +49 761 4520714 & Accessible online at: \\
$\begin{array}{l}\text { E-mail Information@Karger.de } \\
\text { www.karger.com }\end{array}$ & www.karger.com/brc
\end{tabular}

margins. However, general agreement has not been reached on the definition of close or positive margins in this setting. The trials of breast-conservation therapy compared with mastectomy used varying determinations of margin status, from no gross tumor at the resection margin to no cancer cells at the inked surgical margin, to define negative margins [1]. The risk 
of ipsilateral breast tumor recurrence after breast-conserving surgery and radiotherapy (RT) has been shown to be 2-3 times greater in the presence of a positive or close ( $\leq 2 \mathrm{~mm}$ margin) compared with negative margins. However, many other series have not found an increased risk of ipsilateral breast tumor recurrence with a close margin compared with a negative margin [2]. However, breast conservation followed by radiation is the treatment in patients with stage $0-$ II breast cancer, and patients with positive, close or indeterminate margins on excision biopsy typically have to undergo re-excision. Studies show that residual tumor is identified in 32-62\% of re-excision specimens. In an abstract presented by Haideri et al. [3] from the University of Missouri, pathological specimens of patients undergoing re-excision were collected to identify characteristics that may predict residual disease and may filter a subgroup of patients where re-excision could be avoided. Pathological specimens of 159 patients with positive margins undergoing re-excision were reviewed. Age, stage, pathologic type, differentiation, microcalcifications, extensive intraductal component, lymphovascular invasion, estrogen receptor (ER) status, progesterone receptor (PgR) status, HER2/neu, S phase and lymph node involvement were evaluated to predict residual disease. $131(82.3 \%)$ specimens with positive margins underwent re-excision. Residual cancer was identified in 66 (41.5\%) patients. As statistically significant result, the authors finally showed that the pathological grade of differentiation can be an independent predictor of residual disease (well differentiated tumors associated with lower risk), based on a $\mathrm{p}$ value of 0.025 . Stage IIB, ductal carcinoma in situ (DCIS), microcalcifications and extensive intraductal component were frequent in re-excision specimens but not significant.

In conclusion, the authors remark that the incidence of residual carcinoma is significant in patients undergoing re-excision, making it difficult to identify a group with positive margins where re-excision can be avoided. Close or positive margins are indicators of a greater risk of residual disease within the breast on re-excision. The necessity of re-excision for close or positive margins needs to be carefully weighed up for each patient according to the likelihood of finding residual disease in a re-excision specimen, its effect on breast cosmetic, and the magnitude of risk reduction it could afford for local recurrence after RT. In general, patients with positive margins should typically undergo re-excision followed by radiation for comprehensive treatment of their early-stage breast cancer, and the attempt to avoid re-excision based on uncertain prospective markers cannot be included into the daily clinical standard yet.

\section{Interstitial High Dose Rate (HDR) Brachytherapy for Early-Stage Breast Cancer}

Dependent on the timely addition of whole-breast external beam radiation therapy (WBEBRT), neither overall survival
(OS) nor loco-regional control rates are compromised by breast conservation [1]. Until recently, the volume of breast tissue at risk of recurrence has remained undefined, and adjuvant WBEBRT standards of care have consistently recommended irradiation of the entire residual breast. This may be unnecessary based on biological and histopathological evidence, and patterns of failure analyses.

Adjuvant interstitial high dose rate brachytherapy (HDR) for breast cancer, where radiation is restricted to the resectionarea, is an evolving new technique with the potential to re-define breast cancer care. Biggs et al. [4] from the Joe Arrington Cancer Center in Lubbock, Texas presented an abstract with the title 'Interstitial high dose rate brachytherapy for early stage breast cancer' presenting their data on 112 patients who were treated with HDR instead of the standard WBEBRT [4]. HDR for early-stage breast cancer was performed on a large cohort of patients with Tis, T1 and T2 tumors measuring $<3 \mathrm{~cm}$, negative surgical margins, and negative axillary lymph nodes. All of the 112 patients underwent interstitial HDR implant under stereotactic mammographic guidance with conscious sedation and local anesthesia using a template with 3-6 planes and 8-43 needles. Catheter spacing was $1-1.5 \mathrm{~cm}$. Treatment volumes ranged from $25 \mathrm{~cm}^{3}$ to $359 \mathrm{~cm}^{3}$. The breast implant volume received 3,400 cGy in 10 fractions via HDR prescribed to the planning target volume, given twice daily over 5 days. Presenting a median follow-up of 36 months, local recurrence occurred in $2.7 \%$ (3/112). Cosmetic results were described as well to excellent in $85.7 \%(96 / 112)$ of the patients. Wound healing complications developed in 7.1\% (8/112) of the patients. 3 of these patients had received anthracycline-based chemotherapy, and the other 5 had large $\left(>200 \mathrm{~cm}^{3}\right)$ implant volumes and catheter spacing of $1.5 \mathrm{~cm} .2$ patients healed after 6 months of conservative treatment. Surgery was required in 6 patients who developed fat necrosis.

In conclusion, these data provide evidence that utilizing interstitial HDR implants at the site of resection has yielded local recurrence rates and cosmetic results which compare favorably to external brachytherapy of the complete breast in selected patients, maybe avoiding complications specific for external and locally extended radiation therapy. Additionally, Biggs et al. [4] concluded that treatment with anthracycline-based chemotherapy and large $\left(>200 \mathrm{~cm}^{3}\right)$ implant volumes appear to be relative contraindications to interstitial HDR implant.

\section{Vitamin D Deficiency and Bisphosphonate Therapy in Early-Stage Breast Cancer}

Bisphosphonate therapy has been readily accepted as standard of care for patients with metastatic and early-stage disease [5]. There is increasing evidence that vitamin D deficiency might be a risk factor for breast cancer development and increases the risk of hypocalcemia following bisphosphonate therapy [6]. 
Clodronate (CL) prevents bone loss in breast cancer patients. About 10 abstracts dealing with this topic were presented at the 2006 ASCO Annual Meeting. In one abstract, Saarto et al. [7] report their 10-year follow-up data of their CL-bone mineral density (BMD) study in early-stage breast cancer. 268 node-positive breast cancer patients were randomized to oral CL 1.6 g daily, or control group, respectively, for 3 years. Premenopausal patients were treated with adjuvant chemotherapy and postmenopausal women with anti-estrogens (AE), tamoxifen $20 \mathrm{mg}$ or toremifene $60 \mathrm{mg}$, for 3 years. The BMD of the lumbar vertebrae L1-4 (BMD LS $)$ and femoral neck $\left(\mathrm{BMD}_{\mathrm{FN}}\right)$ were measured before the treatment and at 1, 2, 3, 5 and 10 years. At the 10 -year analyses date, 93 patients (53 preand 40 postmenopausal) were eligible. In the premenopausal patients, the $\mathrm{BMD}_{\mathrm{LS}}$ decreased by $12.4 \%$ in the control group and $8.7 \%$ in the CL group in 10 years: $0-3$ years -6.9 vs. $-4.2 \%$ and $3-10$ years -5.5 and $-4.5 \%$, respectively. $\mathrm{BMD}_{\mathrm{FN}} \mathrm{de}-$ creased by 8.8 and $7.2 \%$, respectively: $0-3$ years -2.9 vs. $-2.6 \%$ and $3-10$ years -5.9 vs. $-4.6 \%$, respectively. In the postmenopausal patients, BMDLs decreased by $3.0 \%$ in the $\mathrm{AE}$ and $1.7 \%$ in the $\mathrm{AE}+\mathrm{CL}$ group in 10 years: $0-3$ years -1.5 vs. $+1.2 \%$ and $3-10$ years $-1.5 \%$ vs. $-2.9 \%$, respectively. $\mathrm{BMD}_{\mathrm{FN}}$ decreased by 7.7 and $-6.0 \%$ : $0-3$ years -0.1 vs. $+1.9 \%$ and $3-10$ years -7.6 vs. $-7.9 \%$, respectively. At 10 years, 18 patients had osteoporosis in the lumbar vertebrae and 15 in the femoral neck. Only 4 patients who had osteoporosis at 10 years had normal BMD before the therapy.

As reported previously, CL was shown to prevent bone loss during treatment in pre- and postmenopausal women. However, this beneficial effect seems to be maintained for at least 7 years after treatment termination in premenopausal woman. In postmenopausal women, the effect seems to diminish within time. In good accordance with other presented abstracts, the authors show that especially the bone mineral status at the beginning of adjuvant therapy is an important and significant predictor for the patient's osteoporosis risk. Patients at risk of developing osteoporosis are among those who have pre-treatment osteopenia, i.e. baseline BMD measurement has predictive value.

Hershman et al. [8] from the Columbia University Medical Centre, New York presented their data about the high prevalence of vitamin D deficiency in premenopausal women with early-stage breast cancer. The purpose of this study was to evaluate the prevalence of vitamin D deficiency following the initial diagnosis of breast cancer. Fasting morning blood from premenopausal women with stage I/II breast cancer was analyzed for 25-hydroxyvitamin D, albumin-corrected calcium, phosphate, parathyroid hormone, markers of bone turnover, follicle-stimulating hormone (FSH), luteinizing hormone (LH), estradiol and sex hormone-binding globulin. None of the 36 premenopausal women were taking calcium or vitamin D supplements when integrated into this study. In summary, the authors found no associations between serum 25-hydroxyvitamin D and serum calcium, phosphate, bone turnover markers, or BMD.
In conclusion, suboptimal vitamin D levels are common among premenopausal women with early-stage breast cancer. Significant associations between serum 25-hydroxyvitamin D, sex hormone-binding globulin and free estradiol suggest that serum levels of vitamin D-binding protein may be influencing 25-hydroxyvitamin D measurements. Finally, the authors conclude that serum 25-hydroxyvitamin D should be measured and low levels supplemented before initiating adjuvant bisphosphonate therapy, as vitamin D deficiency may increase the risk of hypocalcaemia. These findings support proper vitamin D supplementation for postmenopausal women in general and for women taking aromatase inhibitors for breast cancer in particular.

\section{Immunologic HER2/neu Therapy, Genomic and Serum Response Prediction for Trastuzumab for Early-Stage Breast Cancer}

Approximately $20 \%$ of all breast cancers show a HER2/neu overexpression, and in the absence of systemic treatment these tumors are associated with a particular aggressive clinical course. The HER2 pathway plays a major role in cell growth and survival, as well as the potential to metastasize. The monoclonal antibody trastuzumab was shown to inhibit the growth of HER2-transformed tumor cells in vitro, and more recently in a rapid 'bench-to-bedside process', big randomized clinical trials (HERA, NCCTG N9831, NSABP B31, BCIRG 006) presented at last year's ASCO Annual Meeting have shown that adjuvant trastuzumab reduces the risk of recurrent HER2-positive disease by approximately 50\% [9-12]. With this established role of trastuzumab in the adjuvant setting, preoperative therapy concepts integrating the HER2 antibody will be used increasingly. 2 of the most critical questions about the optimal use of trastuzumab are the mechanisms of primary and secondary resistance to trastuzumab and the disposability of alternative HER2/neu-associated therapies.

Mittendorf et al. [13] report about the conduction of a phase I clinical trial with an Ii-Key/HER2/neu MHC class II peptide called AE37 (Ii-Key is a 4-amino-acid modification of peptides that has been reported to increase their occupancy of MHC class II molecules and enhance CD4 T cell responses) in early-stage breast cancer patients. The aim of the study was to provide a possible role of AE37 in trastuzumab-containing adjuvant therapy. According to the dose escalation safety trial, patients receive either 100,500 or $1,000 \mu \mathrm{g}$ of AE37 with $250 \mu \mathrm{g}$ of GM-CSF in 6-monthly inoculations. Immunologic response was monitored by peptide-stimulated proliferation and enzyme-linked immuno spot assay (ELISPOT) against IFN- $\gamma$. At the time of presentation, the researchers report that so far 6 patients had been vaccinated. AE37 appears to be safe and well tolerated. A dose-dependent immunologic response has been demonstrated to the Ii-Key modified peptide as well 
as the naturally occurring sequence. These encouraging early results suggest that AE37 may prove to be useful as a CD4specific vaccine either alone or in combination with CD8-specific HER2/neu peptides for improved cancer immunotherapy. Harris et al. [14] presented their data about the possible response prediction to trastuzumab and chemotherapy for earlystage breast cancer with a high-level analysis of genomic data. They investigated whether combined microarray datasets from patients with early breast cancer treated with preoperative trastuzumab and chemotherapy could predict response to therapy. Therefore, 2 cohorts of patients with HER2/neu $3+/ \mathrm{FISH}+$, stage II-III breast cancer were included into this study (trastuzumab and docetaxel $(\mathrm{n}=38)$ / trastuzumab and vinorelbine $(\mathrm{n}=48)$, both for 12 weeks). RNA extraction, amplification and hybridization to Affymetrix U133 chips (Affymetrix, Santa Clara, CA, USA) were successfully performed in 41 patients. Differential expression of genes and chromosomal regions between patients with pathologic complete response ( $\mathrm{pCR}$ ) and those with residual invasive disease were examined. The results showed that gene expression patterns of individual genes showed a weak association with pCR. However, distinct statistically significant chromosomal regions - Chr2p23, Chr6q24, Chr7q33, Chr2p2, Chr12q21.31, Chr14q32.2, Chr1p34.2, Chr8q21.3 - were associated with pCR to trastuzumab therapy $(\mathrm{p}<0.005)$ In summary, the authors provide first evidence that gene expression data can be merged and might be used for the discovery of predictive chromosomal regions associated with response to trastuzumab therapy. If validated, these distinct deregulated chromosomal regions may serve as predictive markers of response to trastuzumab therapy.

Ali et al [15] presented a pooled analysis of 7 trials of first-line trastuzumab therapy (with and without chemotherapy) where serial serum HER2/neu levels were evaluated. The pre- and post-treatment serum from 307 patients were available and processed into further calculations. Both high serum HER2/ neu levels and HER2/neu tumor expression were associated with high histological grade $(\mathrm{p}=0.02$ and $\mathrm{p}<0.0001$, respectively) and negativity of ER $(p=0.0035$ and $p<0.0001)$ and $\operatorname{PgR}(\mathrm{p}=0.0056$ and $\mathrm{p}=0.002)$. At a median follow-up of 2.4 years, 8 deaths and 19 relapses were observed. At univariate analysis, high serum HER2/neu levels (evaluated as continuous variable) were significantly correlated with shorter disease-free survival (DFS) ( $\mathrm{p}=0.0002)$, even if after adjustment for stage and ER status high serum HER2/neu levels were associated with a shorter DFS with borderline signifi- cance $(\mathrm{p}=0.06)$. The results provided a median decrease in serum HER $2 /$ neu levels of $31 \%$ (range $98 \%$ decrease to $239 \%$ increase). In conclusion this study shows that patients with $<20 \%$ decrease in serum HER2/neu levels have decreased benefit from trastuzumab therapy, with decreased time to progression (TTP), duration of response (DRP) and OS and provides evidence for a possible role of HER2/neu measurement as a response prediction marker for a trastuzumab therapy.

\section{Predictive Role of Circulating Tumor Cells in Early- Stage Breast Cancer}

The number of circulating tumor cells before treatment was shown to be an independent predictor of progression-free survival and OS in patients with metastatic breast cancer [16]. Xenidis et al. [17] aimed to evaluate the effect of adjuvant treatment on the peripheral blood CK-19 mRNA circulating tumor cells (CTCs) in patients with early-stage breast cancer. In 119 patients with ER- or/and PgR-positive tumors, CTCs were detected by real-time reverse transcriptase polymerase chain reaction (RT-PCR) assay. Measurements were performed before the initiation and after the completion of adjuvant chemotherapy and every 3 or 6 months during the period of adjuvant tamoxifen administration. The analysis showed that in $17(47 \%)$ of 36 patients with detectable cells in prechemotherapy samples adjuvant chemotherapy failed to eliminate the CTCs. In addition, adjuvant tamoxifen failed to eliminate the CTCs in $8(36.4 \%)$ of 22 patients displaying detectable cells in post-chemotherapy samples. The incidence of clinical relapse was described as significantly $(\mathrm{p}=0.017)$ higher for patients with post-chemotherapy detectable CTCs as well as for patients with persistently detectable CTCs throughout the follow-up period, compared to those who did not (65.3 vs. $7.3 \%$, respectively; $p<0.001$ ). By multivariate analysis the authors show that post-chemotherapy detection of CTCs and their persistence throughout the follow-up period were significantly associated ( $\mathrm{p}=0.001$ and 0.003 , respectively) with early relapse. These results show that the detection of CK-19 mRNA + CTCs after adjuvant chemotherapy and during tamoxifen administration is an independent prognostic factor associated with unfavorable outcome and might be a suitable method of monitoring, bearing the consequence of therapy switch or intensification. It is likely that this technology can aid in appropriate patient stratification and design of tailored treatments.

\section{References}

1 Fisher B, Anderson S, Bryant J, Margolese RG, Deutsch M, Fisher ER, Jeong JH, Wolmark N Twenty-year follow-up of a randomized trial comparing total mastectomy, lumpectomy, and lumpectomy plus irradiation for the treatment of invasive breast cancer. N Engl J Med 2002;347:1233-1241.
2 Park CC, Mitsumori M, Nixon A, Recht A, Connolly J, Gelman R, Silver B, Hetelekidis S, Abner A, Harris JR, Schnitt SJ: Outcome at 8 years after breast-conserving surgery and radiation therapy for invasive breast cancer: influence of margin status and systemic therapy on local recurrence. J Clin Oncol 2000;18:1668-1675.
3 Haideri NA, Moormeier J, Arora A: Positive predictive factors for residual disease in re-excision specimens of early stage breast cancer. ASCO Annu Meet Proc Part I, J Clin Oncol 2006;24: 18S(suppl), abstr 10604. 
4 Biggs S, Anderson P, Mark R, Neumann T, Nair M: Interstitial implant and high dose rate radiation for early stage breast cancer. ASCO Annu Meet Proc Part I, J Clin Oncol 2006;24:18S(suppl), abstr 10551.

$\checkmark 5$ Hillner BE, Ingle JN, Chlebowski RT, Gralow J, Yee GC, Janjan NA, Cauley JA, Blumenstein BA Albain KS, Lipton A, Brown S, American Society of Clinical Oncology: American Society of Clinica Oncology 2003 update on the role of bisphosphonates and bone health issues in women with breast cancer. J Clin Oncol 2003;21:4042-4057.

6 NIH Consensus Development Panel on Osteoporosis Prevention, Diagnosis, and Therapy: Osteoporosis prevention, diagnosis, and therapy. JAMA 2001; 285:785-795.

7 Saarto T, Vehmanen L, Blomqvist C, Elomaa I: 10year follow-up of the efficacy of clodronate on bone mineral density (BMD) in early stage breast cancer. ASCO Annu Meet Proc Part I, J Clin Oncol 2006;24:18S(suppl), abstr 676

8 Hershman DL, McMahon D, Irani D, Cucchiara G, Crew K, Raptis G, Shane E: High prevalence of vitamin D deficiency in pre-menopausal women with early-stage breast cancer. ASCO Annu Meet Proc Part I, J Clin Oncol 2006;24:18S(suppl), abstr 8568.

9 Piccart-Gebhart MJ, Procter M, Leyland-Jones B, Goldhirsch A, Untch M, Smith I, Gianni L, Baselga J, Bell R, Jackisch C, Cameron D, Dowsett M, Barrios $\mathrm{CH}$, Steger G, Huang CS, Andersson M, Inbar M, Lichinitser M, Lang I, Nitz U, Iwata $\mathrm{H}$, Thomssen C, Lohrisch C, Suter TM, Ruschoff J, Suto T, Greatorex V, Ward C, Straehle C, McFadden E, Dolci MS, Gelber RD, Herceptin Adjuvant (HERA) Trial Study Team: Trastuzumab after adjuvant chemotherapy in HER2-positive breast cancer (Hera). N Engl J Med 2005;353:1659-1672.
10 Romond EH, Perez EA, Bryant J, Suman VJ, Geyer CE Jr, Davidson NE, Tan-Chiu E, Martino S, Paik S, Kaufman PA, Swain SM, Pisansky TM, Fehrenbacher L, Kutteh LA, Vogel VG, Visscher DW, Yothers G, Jenkins RB, Brown AM, Dakhil SR, Mamounas EP, Lingle WL, Klein PM, Ingle JN, Wolmark N: Trastuzumab plus adjuvant chemotherapy for operable HER2-positive breast cancer. N Engl J Med 2005;353(16):1673-84

11 Slamon DJ, Leyland-Jones B, Shak S, Fuchs H, Paton V, Bajamonde A, Fleming T, Eiermann W, Wolter J, Pegram M, Baselga J, Norton L: Use of chemotherapy plus a monoclonal antibody against HER2 for metastatic breast cancer that overexpresses HER2. N Engl J Med 2001;344:783-792.

12 Baselga J, Carbonell X, Castaneda-Soto NJ, Clemens M, Green M, Harvey V, Morales S, Barton C, Ghahramani P: Phase II study of efficacy, safety, and pharmacokinetics of trastuzumab monotherapy administered on a 3-weekly schedule. J Clin Oncol 2005;23:2162-2171.

13 Mittendorf EA, Khoo S, Storrer CE, Harris KA, Jama YA, Dehqanzada ZA, Murray ZA, Shriver $\mathrm{CD}$, von Hofe E, Ponniah S: Early results of a phase I clinical trial of an Ii-Key/Her2/neu MHC class II peptide-based vaccine in breast cancer patients. ASCO Annu Meet Proc Part I, J Clin Oncol 2006;24:18S(suppl), abstr 2532.
14 Harris LN, Carter S, You F, Eklund A, Hilsenbeck S, Szallasi Z, Chang J: High level analysis of genomic data reveals complex predictors of response to trastuzumab (T) and chemotherapy for early stage breast cancer. ASCO Annu Meet Proc Part I, J Clin Oncol 2006;24:18S(suppl), abstr 544

15 Ali SM, Esteva FJ, Fornier M, Gligorov J, Harris L, Kostler WJ, Luftner D, Pichon D, Tse C, Lipton A Serum HER-2/neu Study Group: Serum HER2/neu change predicts clinical outcome to trastuzumab-based therapy. ASCO Annu Meet Proc Part I, J Clin Oncol 2006;24:18S(suppl), abstr 500

16 Cristofanilli M, Budd GT, Ellis MJ, Stopeck A Matera J, Miller MC, Reuben JM, Doyle GV, Allard WJ, Terstappen LW, Hayes DF: Circulating tumor cells, disease progression, and survival in metastatic breast cancer. N Engl J Med. 2004;19; 351(8):781-91.

17 Xenidis N, Mavroudis D, Apostolaki S, Perraki M, Stathopoulou A, Lianidou E, Georgoulias V: Effect of adjuvant treatment on the circulating CK-19 mRNA-positive tumor cells in patients with early stage breast cancer. ASCO Annu Meet Proc Part I, J Clin Oncol 2006;24:18S(suppl), abstr 20012 